\title{
Comparison of life loss per death attributable to ambient temperature among various development regions: a nationwide study in 364 locations in China
}

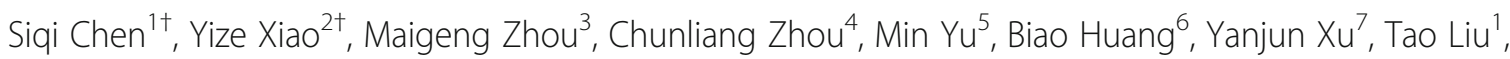
Jianxiong $\mathrm{Hu}^{7}$, Xiaojun $\mathrm{Xu}^{7}$, Lifeng Lin? ${ }^{7}$, Ruying $\mathrm{Hu}^{5}$, Zhulin $\mathrm{Hou}^{6}$, Junhua $\mathrm{Li}^{4}$, Donghui Jin ${ }^{4}$, Mingfang Qin², Qinglong Zhao ${ }^{6}$, Weiwei Gong ${ }^{5}$, Peng Yin ${ }^{3}$, Yiqing X ${ }^{4}$, Jianpeng Xiao ${ }^{1}$, Weilin Zeng ${ }^{1}$, Xing Li ${ }^{1}$, Lingchuan Guo ${ }^{1}$, Yonghui Zhang ${ }^{7}$, Cunrui Huang ${ }^{8}$ and Wenjun $\mathrm{Ma}^{1 *}$ (D)

\begin{abstract}
Background: Several studies have investigated the associations between ambient temperature and years of life lost (YLLs), but few focused on the difference of life loss attributable to temperature among different socioeconomic development levels.

Objectives: We investigated the disparity in temperature-YLL rate relationships and life loss per death attributable to nonoptimal temperature in regions with various development levels.

Methods: Three hundred sixty-four Chinese counties or districts were classified into 92 high-development regions (HDRs) and 272 low-development regions (LDRs) according to socioeconomic factors of each location using Kmeans clustering approach. We used distributed lag non-linear models (DLNM) and multivariate meta-analysis to estimate the temperature-YLL rate relationships. We calculated attributable fraction (AF) of YLL and temperaturerelated average life loss per death to compare mortality burden of temperature between HDRs and LDRs. Stratified analyses were conducted by region, age, sex and cause of death.
\end{abstract}

\footnotetext{
* Correspondence: mawj@gdiph.org.cn

${ }^{\dagger}$ Siqi Chen and Yize Xiao contributed equally to this work.

'Guangdong Provincial Institute of Public Health, Guangdong Provincial

Center for Disease Control and Prevention, No.160, Qunxian Road, Panyu

District, Guangzhou 511430, Guangdong, China

Full list of author information is available at the end of the article
}

(c) The Author(s). 2020 Open Access This article is licensed under a Creative Commons Attribution 4.0 International License, which permits use, sharing, adaptation, distribution and reproduction in any medium or format, as long as you give appropriate credit to the original author(s) and the source, provide a link to the Creative Commons licence, and indicate if changes were made. The images or other third party material in this article are included in the article's Creative Commons licence, unless indicated otherwise in a credit line to the material. If material is not included in the article's Creative Commons licence and your intended use is not permitted by statutory regulation or exceeds the permitted use, you will need to obtain permission directly from the copyright holder. To view a copy of this licence, visit http://creativecommons.org/licenses/by/4.0/. The Creative Commons Public Domain Dedication waiver (http://creativecommons.org/publicdomain/zero/1.0/) applies to the data made available in this article, unless otherwise stated in a credit line to the data. 


\begin{abstract}
(Continued from previous page)
Results: We found that non-optimal temperatures increased YLL rates in both HDRs and LDRs, but all subgroups in LDRs were more vulnerable. The disparity of cold effects between HDRs and LDRs was significant, while the difference in heat effect was insignificant. The overall AF of non-optimal temperature in LDRs $[A F=12.2,95 \%$ empirical confidence interval (eCl):11.0-13.5\%] was higher than that in HDRs (AF = 8.9, 95\% eCl: 8.3-9.5\%). Subgroups analyses found that most groups in LDRs had greater AFs than that in HDRs. The average life loss per death due to non-optimal temperature in LDRs (1.91 years, 95\% eCl: 1.72-2.10) was also higher than that in HDRs (1.32 years, $95 \% \mathrm{eCl}: 1.23-1.41$ ). Most of AFs and life loss per death were caused by moderate cold in both HDRs and LDRs.
\end{abstract}

Conclusions: Mortality burden caused by temperature was more significant in LDRs than that in HDRs, which means that more attention should be paid to vulnerable populations in LDRs in planning adaptive strategies.

Keywords: Temperature, Years of life lost, Mortality burden, Socioeconomic development level

\section{Introduction}

Climate change is widely recognized as one of the major public health threats of the twenty-first century. The Intergovernmental Panel on Climate Change has projected that global warming is likely to reach $1.5^{\circ}$ between 2030 and 2052 if climate change continue the current rate [1]. A link between ambient temperature and mortality has been reported in numerous studies [2,3]. Those studies have found that temperature-mortality curves are usually $U$ or $J$ shaped, which means that non-optimal temperatures, both low and high, lead to excess mortality [2]. Other studies further showed that socioeconomic status such as individual income and education attainment had a significant modifying effect on the association $[4,5]$.

Most previous studies used death count as a primary health outcome to examine the effects of ambient temperature exposure $[2,6]$. This indicator takes only the number of deaths into account and not the age at death. Therefore, it does not represent the real burden of exposure to ambient temperature. Years of life lost (YLLs), an important component of disability adjusted life years (DALY), is an indicator of premature death used to evaluate the burden of disease. YLL is a more informative indicator because it puts more weight on death at young age than death at old age [7]. However, very few studies estimated the effects of temperature on YLLs, and most of them focused on urban areas [8]. Moreover, in previous studies, YLLs caused by temperature could not be comparable because total YLLs largely depends on the population size of each study location. YLLs should be adjusted by population, such as using YLL rate (i.e., YLL $/ 10^{5}$ population), for comparison among different regions and populations.

China is a vast country where socioeconomic status is geographically heterogeneous. Most studies have recognized that socioeconomic factors are very important health determinants. Several studies have reported that socioeconomic factors independently affected the association of temperature with mortality counts $[5,9,10]$. For instance, several studies reported that temperaturemortality relationships had difference between urban and rural areas [11-13], gross domestic product (GDP) and average educational years also could explain spatial heterogeneity of temperature-related effects $[10,14,15]$. Based on these, we hypothesize that low socioeconomic development regions (LDRs) maybe more vulnerable to ambient temperature than high development regions (HDRs), which has not been examined in the previous studies at national level.

To test the hypothesis, we conducted a national study including 364 locations in China. We first classified the locations into different development levels regions according to urbanization level, level of educational attainment and GDP per capita of each location using K-means clustering algorithm. Then, we compared temperature-YLL rate associations and life loss per death attributable to non-optimal temperature among different development levels. Our findings will be helpful to identify vulnerable populations in regions requiring protection.

\section{Material and methods Study locations}

The study included 364 counties or districts covering seven geographical regions around mainland China (Fig. 1). Study locations in Yunnan, Guangdong, Hunan, Zhejiang, and Jilin provinces were selected based on the provincial mortality surveillance system. Locations in other provinces were selected based on the China's Disease Surveillance Points System (DSPs). DSPs is administrated by the Chinese Center for Disease Control and Prevention (CDC), and the detailed information on DSPs was described elsewhere $[16,17]$. In order to assure enough statistical power, only locations with a population size over 200,000 or mortality rates larger than $4 \%$ were included [18]. The 364 locations were classified into 92 HDRs and 272 LDRs according to percentage of urban dwellers, average years of education and GDP per capita of 


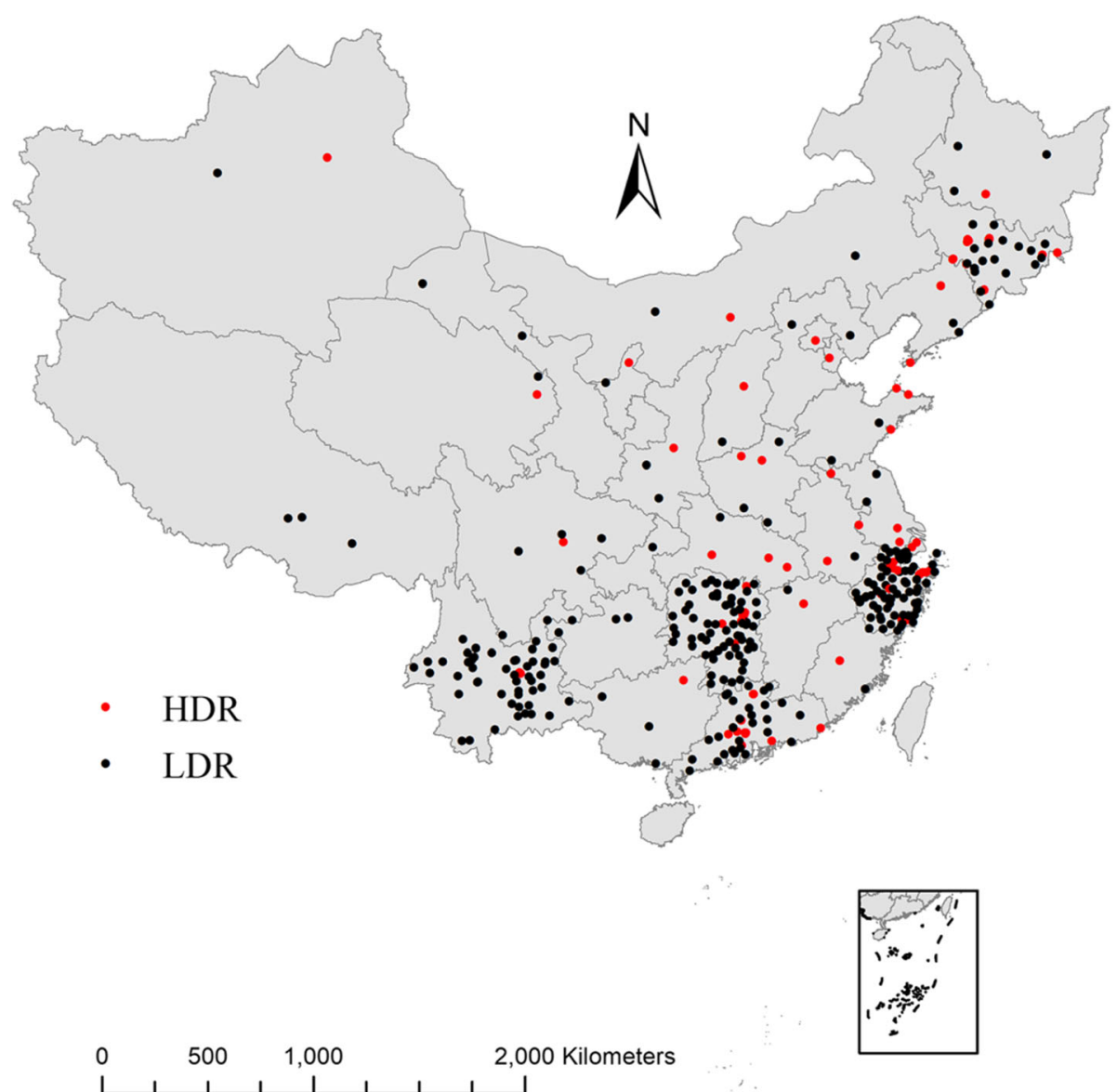

Fig. 1 Distribution of 92 HDRs and 272 LDRs in the present study. HDR: high-development region; LDR: low-development region

each location using clustering methods. The detailed information on development level is described below.

Socioeconomic development is a comprehensive concept including social, economic, humanities development. Since many socioeconomic indicators at the county or district level is hard to obtain in China, we collected three available and representative socioeconomic indicators of each location, including percentage of urban dwellers for urbanization level, average years of education for education level and GDP per capita for economic level to evaluate socioeconomic development level. In order to ensure data-driven rather than arbitrary classification of development level, we employed Kmeans clustering analysis to classify development level. The K-means clustering algorithm is an unsupervised machine learning method for data clustering analysis. The main idea is the minimization of the distance within the clusters utilizing an iterative method [19]. In our study, the dataset was first divided into $\mathrm{K}$ clusters according to an arbitrarily chosen initial cluster center with the minimum distance principle; the average of each cluster then become new cluster centers for re- dividing. In such an iterative manner, the final clustering was developed when the cluster centers no longer changed. We determined the optimal number of clusters based on Nbclust, an $\mathrm{R}$ package which provides 30 indices for determining the best number of clusters and proposes the best clustering scheme from the different results obtained by varying all combinations of number of clusters (from 2 to 7 ) and distance measures [20]. The results showed that two clusters are optimal (Figure S1, see Supplementary material), which represents for HDRs and LDRs (Table S1, see Supplementary material).

\section{Data collection}

Daily death records in locations from Yunnan, Guangdong, Hunan, Zhejiang, and Jilin provinces (from January 1, 2013 to December 31, 2017) were collected from the corresponding provincial CDC and daily death data of other locations (from January 1, 2006 to December 31 , 2011) were collected from Chinese CDC, as described previously [18]. All deaths were classified based on the sole primary diagnosis coded by International Classification of Diseases, 10th Revision (ICD-10) 
including total non-accidental causes (codes: A00-R99), cardiovascular disease (CVD, codes I00-I99) and respiratory disease (RESP, codes J00-J98).

We calculated individual YLLs by matching the age and sex of every death to the life table for corresponding province (Table S2, see Supplementary material). The provincial life table was calculated based on the mortality data and demographical information collected from 2010 Population Census of China. Then daily YLLs of each location were quantified by summing all individual YLLs on the same day. We stratified daily YLLs by cause of death (non-accidental causes, CVD or RESP), sex (male or female), age (0-64 or 65+ years old), and region (northern China or southern China, divided by the north-south demarcation zone in China, which was developed based on the Geographic Information System with some quantitative methods) [21]. We further computed daily YLL rate (per $10^{5}$ populations) of each subgroup by dividing daily YLLs by the population size of the group, and multiplying $10^{5}$.

Daily mean temperature and relative humidity data from 698 climate stations across China were derived from the China Meteorological Data Sharing Service System (http://data.cma.cn/, Figure S2, see Supplementary material). We employed the Australian National University Splines (ANUSPLIN), an interpolation package based on the thin plate smoothing spline function, to interpolate the daily temperature grid and daily relative humidity grid at $0.01^{\circ} \times 0.01^{\circ}$ resolution for all of China from 698 daily weather station observations. Longitude and latitude were considered as independent spline variables and elevation was regarded as a covariate. Ten-fold cross-validation confirmed the good prediction accuracy of the interpolation method for daily mean temperature $\left[R^{2}=0.96\right.$, root mean squared prediction error $(\mathrm{RMSE})=2.37^{\circ} \mathrm{C}$ ] and daily relative humidity $\left(R^{2}=0.81\right.$, $\left.R M S E=7.7 \%\right)$ (Figure S3, see Supplementary material). Daily mean temperatures and relative humidity data from all 364 studied locations were extracted from the corresponding interpolated grid.

Since $\mathrm{PM}_{10}$ was the only available air pollutant during the whole study period (2006-2017), so we used it as a represent of air quality. Daily average $\mathrm{PM}_{10}$ data during 2006-2017 were obtained from the China National Environmental Monitoring Centre. Since the air quality monitoring system did not cover all study locations, we employed a random forest model to predict the daily $\mathrm{PM}_{10}$ of each location using the following predictors: daily mean temperature, daily $\mathrm{RH}$, latitude, longitude, altitude, population density, length of road, types of land use and GDP per capital at each monitoring station using a radius of $1300 \mathrm{~m}$ [22, 23]. One smooth temporal basis function was also included in the model to control long-term and seasonal trend of $\mathrm{PM}_{10}$ concentrations.
The result of ten-fold cross-validation for the model showed that the $\mathrm{R}^{2}$ was 0.78 and RMSE was $13.2 \mu \mathrm{g} /$ $\mathrm{m}^{3}$ (Figure S3, see Supplementary material). The population density data in 2015 were obtained from GeoData Institute in University of Southampton (www.worldpop.org. uk), and the geographic information system (GIS) (geographic map, road density, land use data and GDP per capita) were obtained from the Data Center for Resources and Environmental Sciences (http://www.resdc.cn).

GDP data and population data for each location were gathered from the Statistical Yearbook at the provincial and city level. Other county-level socioeconomic characteristics including average years of education and urban population size were obtained from the 2010 Population Census in China.

\section{Statistical analysis}

\section{Distributed lag non-linear model fitting}

A two-stage analytic approach was employed to investigate the association between temperature and YLL rates. In the first stage, we estimated the location-specific association of temperature-YLL rate using distributed lag non-linear model framework (DLNM) [24] combined with Gaussian distribution function. The DLNM models were described as follows:

$$
\begin{aligned}
E\left(Y_{t}\right)= & a+c b\left(\mathrm{Tm}_{\mathrm{t}}, \operatorname{lag}\right)+n s\left(\mathrm{time}_{\mathrm{t}}, d f\right) \\
& +n s\left(\mathrm{Rh}_{\mathrm{t}}, d f\right)+\beta_{1} \mathrm{DOW}_{\mathrm{t}}
\end{aligned}
$$

where $Y_{\mathrm{t}}$ refers to the YLL rate on day $\mathrm{t} ; c b\left(\mathrm{Tm}_{\mathrm{t}}, \mathrm{lag}\right)$ refers to the cross-basis function of daily temperature, defined as a quadratic B-spline with three knots (10th, 50th, 90th) of location-specific temperature distributions, and a natural cubic B-spline with an intercept and three internal knots placed at equally spaced values in the log scale; $n s$ $\left(\right.$ time $\left._{\mathrm{t}}, d f\right)$ means natural cubic B spline function of time with 7 degrees of freedom $(d f)$ per year for the seasonal and long-term trend; $n s\left(\mathrm{Rh}_{\mathrm{t}}, d f\right)$ means a natural cubic Bspline function of relative humidity with $3 d f ; \beta_{1} \mathrm{DOW}_{\mathrm{t}}$ refers to a categorical variable of day of the week. Previous studies suggested that effects of cold often appear several days later and last for about 2 weeks, and hence, we chose 21 days as the maximum lag [6].

As DLNM is a two-dimensional function considering non-linear exposure-response relationship and delayed effect simultaneously [24], we then reduced the fullassociation to the overall exposure-response association to cumulate full effects during the lag period. This step reduces the number of parameters for pooling in the second-stage meta-analysis.

In the second stage, we pooled the location-specific exposure-response associations using multivariate metaanalytical model with random effects models. The best linear unbiased prediction (BLUP) of location-specific 
cumulative associations between temperature and YLL rate were derived by use of the fitted meta-analytical model. The BLUP method makes use of a trade-off between the location-specific association and the pooled association to increase the preciseness of prediction, especially in location with small daily mortality counts [2].

\section{Calculation of mortality burden of non-optimal temperatures}

The minimum YLL rate temperature (MYT) and the corresponding minimum YLL rate temperature percentile (MYP) in each location were obtained from the corresponding BLUP of overall temperature-YLL rate associations and were defined as the optimal temperatures. We used the MYT as the reference for calculating the attributable YLL rate by re-centring the quadratic B spline that models the exposure-response. And the daily attributable YLL in each location was the production of attributable YLL rate and population size. The total attributable YLL was the sum of the attributable YLL for each day in time series. Its radio to the sum of YLLs during the study periods provides total attributable fraction (AF) [2], and its radio to the sum of daily death provides temperature-related life loss per death. We also estimated the AFs and life loss per death related to extreme cold, moderate cold, moderate heat, and extreme heat by summing the subsets of days with corresponding temperatures range (defined as $\leq 2.5$ th percentile, 2.5th percentile to the MYT, MYT to 97.5th percentile, and $\geq$ 97.5th percentile of daily temperature, respectively). Empirical confidence intervals (eCIs) were obtained through Monte Carlo simulations with the assumption of a multivariate normal distribution of the BLUP of the reduced coefficients $[25,26]$.

\section{Sensitivity analysis}

To check the robustness of all models, we conducted sensitivity analysis by varying the maximum lag periods and the $d f$ for time trend. We also investigate temperatureYLL rate using different temperature measures.

Since death datasets were collected from different data source, we perform a sensitivity analysis to compare the temperture-YLL rate associations in different death dataset.

$\mathrm{R}$ software version 3.6.0 was used to performed data analysis, with the "stats" package and "Nbclust" package for the K-means clustering algorithm, the "dlnm" package for constructing the DLNM model, and the "mvmeta" package for multivariate meta-analysis.

\section{Results}

\section{Descriptive statistics}

Summary statistics of daily YLL rates (per $10^{5}$ ), daily meteorological variables, and socioeconomic and demographic characteristics for HDRs and LDRs are presented in Table 1. The study had 10.7 million YLLs. Generally, there were higher average YLL rates in LDRs than in HDRs. Compared with HDRs, the daily mean temperature in LDRs was 1.0 degree Celsius higher. Socioeconomic factors in HDRs were notably higher than that in LDRs.

\section{Temperature-YLL rate relationships}

Figure 2 shows the pooled associations between temperature and YLL rate for total population in LDRs and HDRs of China as a whole, northern China and southern China, and Fig. 3 displays the stratified analyses of the temperature-YLL rate associations in LDRs and HDRs by age, sex, and cause of death. For all above

Table 1 Summary statistics of daily weather factors, YLL rate and socioeconomic characteristics

\begin{tabular}{|c|c|c|}
\hline Development level & HDRs & LDRs \\
\hline Number of locations & 92 & 272 \\
\hline \multicolumn{3}{|l|}{ Daily YLL rate (Mean (SD)) } \\
\hline Total population & $20.5(13.1)$ & $24.7(16.6)$ \\
\hline Age 0-64 & 12.0(11.8) & $15.0(15.4)$ \\
\hline Age65+ & $98.7(70.3)$ & $110.9(75.5)$ \\
\hline Males & 24.3(19.2) & $29.1(23.6)$ \\
\hline Females & $16.7(15.4)$ & 20.1(19.9) \\
\hline Cardiovascular & $7.1(7.0)$ & $8.7(8.5)$ \\
\hline Respiratory & $1.7(2.8)$ & $2.6(4.4)$ \\
\hline Northern China & $21.0(14.4)$ & $25.7(24.6)$ \\
\hline Southern China & $20.1(12.7)$ & $24.5(14.8)$ \\
\hline \multicolumn{3}{|l|}{ Daily mean temperature $\left({ }^{\circ} \mathrm{C}\right)$} \\
\hline Mean (SD) & 15.3(10.8) & 16.3(9.5) \\
\hline Minimum & -30.6 & -32.3 \\
\hline 2.5th percentile & -11.7 & -6.2 \\
\hline 25th percentile & 8.3 & 10.1 \\
\hline 50th percentile & 17.1 & 17.7 \\
\hline 75th percentile & 23.7 & 23.4 \\
\hline 97.5th percentile & 30.6 & 30.2 \\
\hline Maximum & 35.5 & 35.6 \\
\hline Relative humidity [\%, Mean (SD)] & $71.7(14.5)$ & 73.6(13.7) \\
\hline \multicolumn{3}{|l|}{ Socioeconomic and demographic characteristics } \\
\hline Population $\left(10^{5}\right)$ & 525.0 & 1501.5 \\
\hline Percent population of males [\%, Mean (SD)] & $50.5(2.3)$ & $51.2(1.2)$ \\
\hline $\begin{array}{l}\text { Percent population }>65 y \text { of age }[\% \text {, Mean } \\
\text { (SD)] }\end{array}$ & $10.3(2.9)$ & $10.2(2.5)$ \\
\hline Percent of urban dweller [\%, Mean (SD)] & $86.3(14.1)$ & $41.2(14.4)$ \\
\hline Average years of education [Mean (SD)] & $10.7(1.0)$ & $8.3(0.8)$ \\
\hline GDP per capita [thousand RMB, Mean (SD)] & $55.2(34.1)$ & $24.8(14.2)$ \\
\hline
\end{tabular}

Notes: HDRs High-development regions, LDRs Low-development regions, SD Standard deviation, YLL rate Years of life lost per $10^{5}$ populations, GDP Gross domestic product 


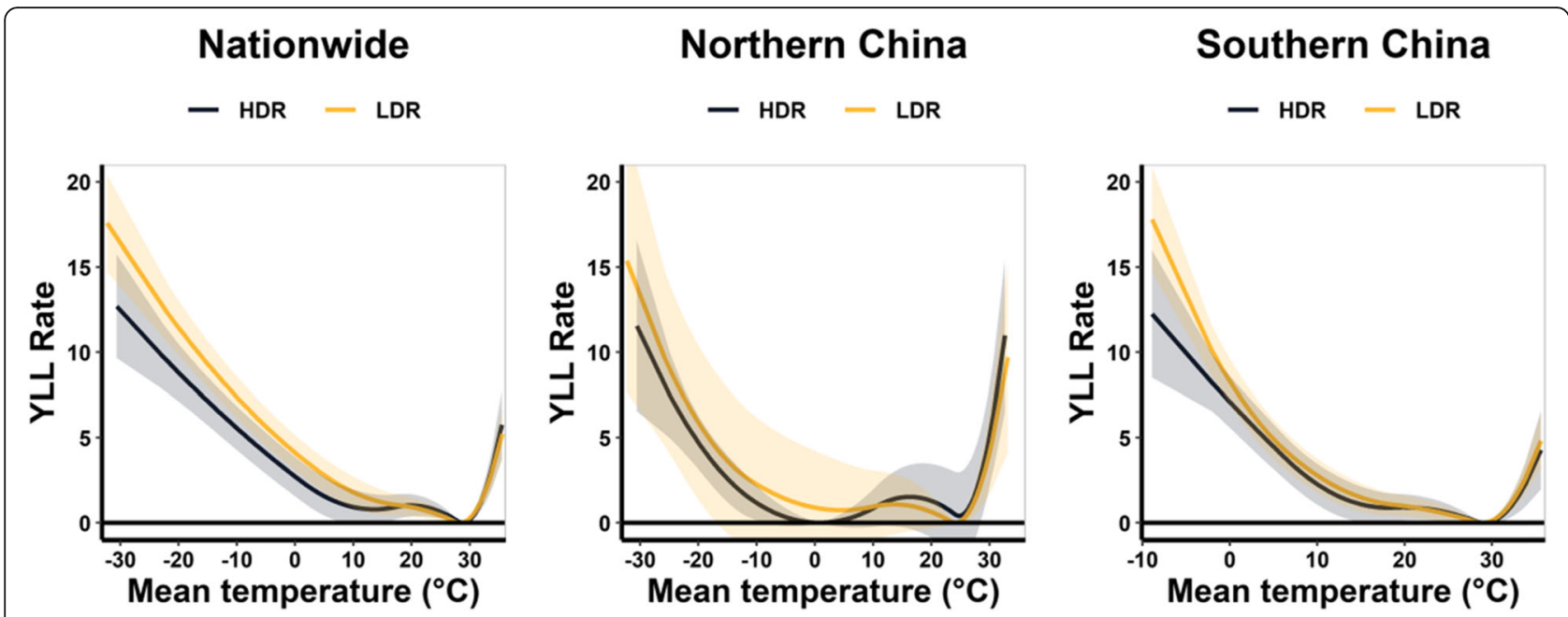

Fig. 2 Overall cumulative temperature-YLL rate associations along lag 0-21 days with 95\% confidence interval (CI). HDR: high-development region; LDR: low-development region; YLL rate: years of life lost per $10^{5}$ population

groups, we found that the attributed YLL rates below MYT were higher in LDRs compared with HDRs, while above MYT they were very close.

Table 2 further displayed the attributable YLL rates for extreme cold (2.5th percentile of temperature distribution) and extreme heat (97.5th percentile of temperature distribution). Compared with extreme heat-related YLL rate, the HDR-LDR disparity of extreme cold-related YLL rate were more significant. This HDRs-LDRs discrepancy for the elderly ( $\geq 65$ years old) and cardiovascular disease was more distinct than that for young population and respiratory disease.

\section{Comparison of temperature-related mortality burden between LDRs and HDRs}

AFs and life loss per death associated with non-optimal temperatures in HDRs and LDRs are shown in Tables 3 and 4, respectively. Generally, temperature-related mortality burden was higher in LDRs compared with HDRs. The overall AFs were 8.9\% (95\% eCI: 8.3-9.5\%) in HDRs and $12.2 \% \quad(95 \%$ eCI: $11.0-13.5 \%)$ in LDRs, and temperature-related life loss per death were 1.32 years (95\% eCI: 1.23-1.41) in HDRs and 1.91 years (95\% eCI: 1.72-2.10) in LDRs. Cold-related AFs and life losses per death were higher in LDRs than those in HDRs for most populations excerpt patients with respiratory diseases. Cold-related AFs or life loss per death (below MYT) were much higher than heat-related AFs (above MYT) or life loss per death in both HDRs and LDRs.

AFs and life loss per death were further estimated for four temperature components: extreme cold, moderate cold, moderate heat, and extreme heat (Fig. 4, Table S3, Table S4, see Supplementary material). Extreme temperature contributed to 0.19 years life loss per death in HDRs and 0.22 years life loss per death in LDRs. Moderate cold contributed to majority of mortality burden, with a total AF of $7.7 \%$ in HDRs and a total AF of 8.3\% in LDRs, and an average of 1.11 years life loss per death from temperature in HDRs and 1.45 years life loss per death from temperature in LDRs were associated with moderate cold.

\section{Sensitivity analysis}

Temperature-YLL rate curves for HDRs and LDRs were performed when varying the $d f \mathrm{~s}$ for time trend, lag structure and temperature measures (Figure S4, see Supplementary material). Figure S5 show temperature-YLL association for HDRs and LDRs in different datasets. The sensitivity analysis suggested that our main results were relatively stable.

\section{Discussion}

To the best of our knowledge, this is the first multilocations time-series study to investigate the disparity in temperature-YLL rate relationship and life loss per death attributable to temperature among different development regions in a developing country. We found an apparent disparity in YLL rates caused by temperature between HDRs and LDRs. Moreover, attributable YLL rates for cold temperature were higher in LDRs than that in HDRs, but heat-related YLL rates were very close between the two development regions.

Human Development Index (HDI) is a summary measure of human development in the literature [27]. In the study, we did not define development level using HDI for data unavailability, which may influence the comparison of our findings with other studies. However, the three indicators we chose to classify development levels are appropriate 

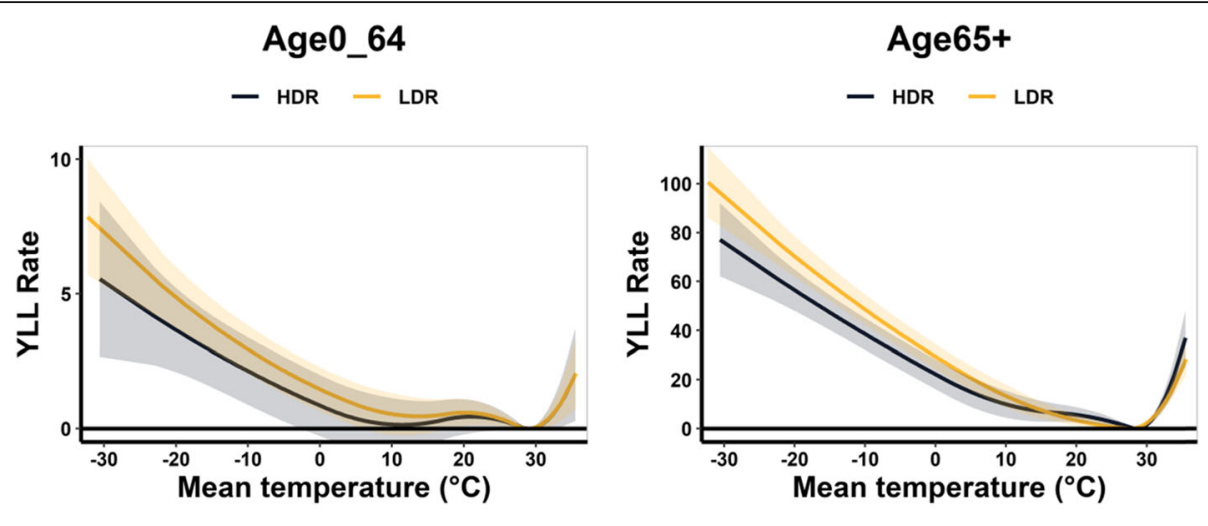

Males

\section{Females}
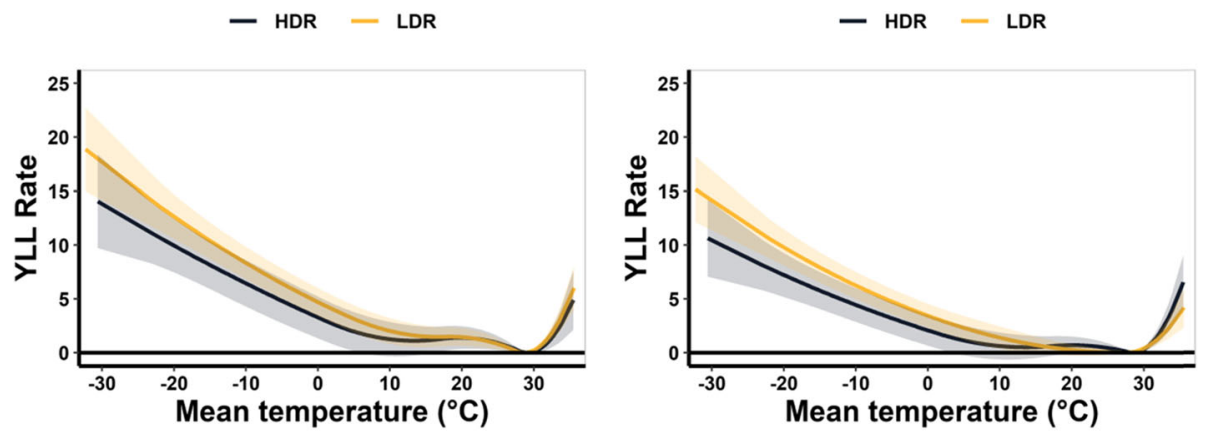

Cardiovascular disease
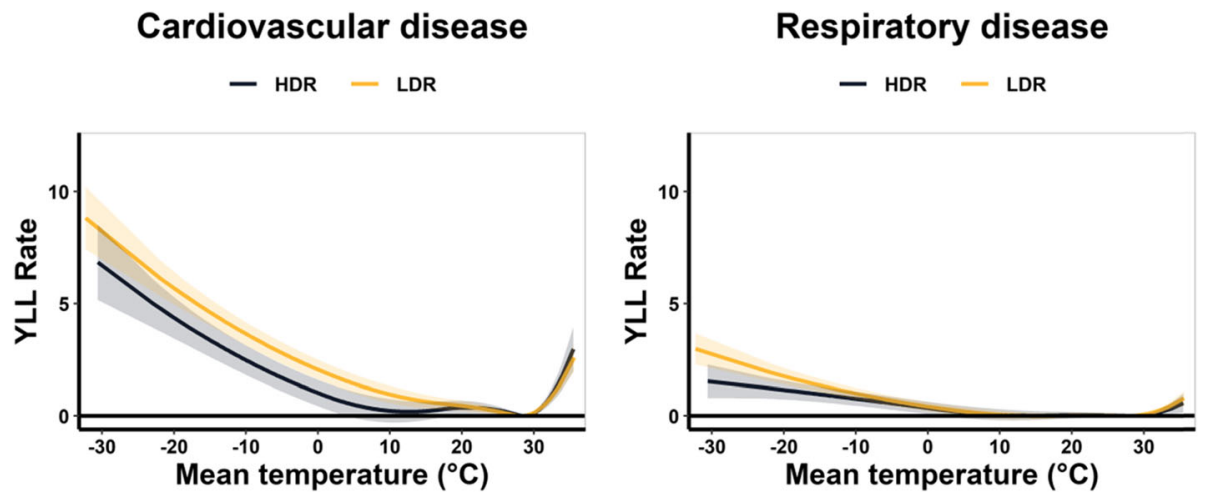

Fig. 3 Pooled temperature-YLL rate associations along lag 0-21 days with 95\% confidence intervals (CI) by age, sex, and cause of death in HDR and LDR. YLL rate: years of life lost per $10^{5}$ populations. HDR: high-development region; LDR: low-development region

because they reflect different aspects of socioeconomic development level including economic status, urbanization level and education level. We classified all study locations into different development levels using K-means clustering algorithm rather than simple equisection of the three indicators because $\mathrm{K}$-means is a scientific cluster analysis with a clear mechanism [28-30].

Our findings showed that the attributable YLL rates were greater in LDRs than that in HDRs for all subgroups. This finding is consistent with several previous studies that investigated urban-rural mortality disparity using relative risk (RR) [11-13]. For example, a study in Zhejiang, China found that the RRs associated with temperature were higher in rural areas than that in urban areas for all causes of death, the elderly ( $\geq 65$ years old), and both sexes [12]. Hajat et al. found that lower economic status [e.g., gross domestic product (GDP)] associated with higher heat risk $[14,15]$. Low average education also have been found worsen cold- and heatrelated mortality burden [10]. Possible reasons for this finding were the potential differences in social environment and living conditions among different development 
Table 2 Minimum YLL temperature (MYT) and attributable YLL $(95 \% \mathrm{Cl})$ rate associated with non-optimal temperatures by development level

\begin{tabular}{|c|c|c|c|c|c|c|}
\hline \multirow[t]{2}{*}{ Subgroups } & \multicolumn{2}{|c|}{ MYT [ $\left.{ }^{\circ} \mathrm{C}, \mathrm{MYP}(\%)\right]$} & \multicolumn{2}{|c|}{ Extreme cold effect } & \multicolumn{2}{|c|}{ Extreme heat effect } \\
\hline & HDR & LDR & HDR & LDR & HDR & LDR \\
\hline Nationwide & 28.8(92.9) & $28.3(92.5)$ & $5.0(3.8-6.3)$ & $6.7(5.5-7.9)$ & $0.3(0.1-0.5)$ & $0.4(0.2-0.6)$ \\
\hline Northern China & $0.8(28.8)$ & $24.1(92.3)$ & $3.8(2.4-5.3)$ & $4.9(0.4-9.3)$ & $1.0(-1.6-3.6)$ & $0.7(0.2-1.3)$ \\
\hline Southern China & $29.1(93.5)$ & 28.8(92.4) & $5.8(4.4-7.2)$ & $6.5(5.3-7.7)$ & $0.2(0.0-0.5)$ & $0.3(0.1-0.5)$ \\
\hline Age 0-64 & 29.0(93.4) & 28.9(94.3) & $1.9(0.7-3.2)$ & $2.6(1.8-3.5)$ & $0.1(-0.1-0.2)$ & $0.1(0.0-0.2)$ \\
\hline Age65+ & $28.5(92.0)$ & $27.7(90.5)$ & $35.5(29.2-41.9)$ & $44.7(38.8-50.6)$ & $2.4(1.3-3.4)$ & $3.0(2.0-4.0)$ \\
\hline Males & $29.1(93.7)$ & 28.7(93.7) & $5.8(3.7-8.0)$ & $7.6(6.1-9.0)$ & $0.2(0.0-0.4)$ & $0.3(0.1-0.5)$ \\
\hline Females & $28.5(92.0)$ & $27.4(89.4)$ & $4.0(2.4-5.5)$ & $5.7(4.4-6.9)$ & $0.4(0.2-0.7)$ & $0.5(0.2-0.8)$ \\
\hline Cardiovascular diseases & 28.6(92.3) & $28.3(92.5)$ & $2.2(1.5-2.8)$ & $3.3(2.8-3.8)$ & $0.2(0.1-0.3)$ & $0.2(0.1-0.3)$ \\
\hline Respiratory diseases & 28.4(91.7) & $27.7(90.5)$ & $0.7(0.4-1.0)$ & $0.9(0.6-1.1)$ & $0.0(0.0-0.1)$ & $0.1(0.0-0.1)$ \\
\hline
\end{tabular}

Notes: MYT Minimum YLL rate temperature, MYP Minimum YLL rate percentile of the daily temperature

Extreme cold: 2.5 th percentile of temperature distribution; nationwide: $-8.2{ }^{\circ} \mathrm{C}$, northern China: $-18.0^{\circ} \mathrm{C}$, southern $\mathrm{China:} 2.4^{\circ} \mathrm{C}$

Extreme heat: 97.5 th percentile of temperature distribution; nationwide: $30.3{ }^{\circ} \mathrm{C}$, northern China: $26.6^{\circ} \mathrm{C}$, southern $\mathrm{China:} 30.6^{\circ} \mathrm{C}$

regions such as population structure and density, lifestyle and availability to adequate health care services or home air conditioners. This result suggests that LDRs are more vulnerable to non-optimal temperature exposure and more resources should be allocated in these regions to protect vulnerable populations. For instance, it is necessary to improve health care services and provide adaptation assistance for vulnerable populations such as the elderly and patients with cardiopulmonary diseases in LDRs.

We further found that cold-related YLL rates were higher in LDRs compared with HDRs, which was consistent with previous findings that socioeconomic factors have a modifying effect on the temperature-mortality count relationship [10, 31]. However, the heat-related YLL rates were similar between HDRs and LDRs, which implies that development level does not play an important role in heat-related YLL rates. This result may partially be explained by urban heat-island (UHI) effect, which has been found to have an important impact on heat-related mortality [32]. Several previous studies reported that HDRs characterized by more urbanized areas and higher population densities were more vulnerable to heat $[5,10]$. Though populations in HDRs might not be vulnerable to high temperature because of better adaption capacity $[11,33]$, the presence of UHI effect in HDRs may offset that capacity. In the context of rapid urbanization in most parts of China, effective public health policies designed to reduce UHI effects are necessary in HDRs to mitigate the health impacts of high temperature exposure.

We found that less YLLs attributed to non-optimal temperature in HDRs $(8.8 \%)$ than in LDRs $(10.4 \%)$. This is understandable because there are higher attributable YLL rates at each temperature in the LDRs compared with HDRs. We further calculated life loss per death attributed to non-optimal temperature and found they were high in HDRs than that in LDRs. Temperaturerelated life loss per death is a more informative indicator to understand health impact of temperature. Generally,

Table 3 AFs attributable $(95 \% \mathrm{eCl})$ to non-optimal temperatures by development level

\begin{tabular}{|c|c|c|c|c|c|c|}
\hline \multirow[t]{2}{*}{ Subgroups } & \multicolumn{2}{|l|}{ Total } & \multicolumn{2}{|l|}{ Cold } & \multicolumn{2}{|l|}{ Heat } \\
\hline & HDRs & LDRs & HDRs & LDRs & HDRs & LDRs \\
\hline Nationwide & $8.9(8.3-9.5)$ & $12.2(11.0-13.5)$ & $8.5(7.9-9.1)$ & 10.4(9.3-11.4) & $0.4(0.3-0.5)$ & $1.9(1.1-2.6)$ \\
\hline Northern China & 7.3(4.8-9.7) & 14.9(11.7-18.7) & $4.0(2.3-5.7)$ & $8.0(6.0-9.9)$ & $3.3(1.4-5.1)$ & $6.9(4.1-10.3)$ \\
\hline Southern China & $9.8(8.9-10.8)$ & $12.5(11.1-13.9)$ & $9.5(8.6-10.4)$ & 10.7(9.4-11.8) & $0.3(0.2-0.4)$ & $1.8(1.0-2.6)$ \\
\hline Age 0-64 & $6.5(3.7-9.1)$ & $9.4(7.7-11.2)$ & $5.3(3.7-6.7)$ & $7.5(6.0-8.9)$ & $1.3(-1.0-3.4)$ & $2.0(1.0-3.0)$ \\
\hline Age65+ & 13.3(12.1-14.6) & 16.2(15.0-17.4) & 12.6(11.5-13.9) & 14.4(13.4-15.4) & $0.7(0.4-0.9)$ & $1.8(1.0-2.6)$ \\
\hline Males & $10.2(8.7-11.7)$ & 11.7(10.2-13.2) & $9.6(8.2-11.0)$ & $10.1(9.2-11.0)$ & $0.6(0.2-1.0)$ & $1.6(0.5-2.8)$ \\
\hline Females & $8.2(7.4-9.0)$ & $11.1(9.6-12.6)$ & $7.7(6.8-8.5)$ & $9.6(8.3-10.9)$ & $0.6(0.5-0.6)$ & $1.5(0.7-2.5)$ \\
\hline Cardiovascular diseases & 11.3(9.7-12.9) & 14.6(12.8-16.5) & $9.8(8.2-11.2)$ & $12.4(11.5-13.2)$ & $1.6(0.9-2.2)$ & $2.3(0.7-3.8)$ \\
\hline Respiratory diseases & 13.3(10.2-16.4) & $13.9(10.1-17.3)$ & $11.2(9.0-13.4)$ & $8.0(6.9-9.0)$ & $2.1(-0.4-4.6)$ & $5.9(2.4-9.2)$ \\
\hline
\end{tabular}

Notes: HDRs High-development regions, LDRs Low-development regions

Cold: temperature below minimum YLLs temperature; Heat: temperature above minimum YLLs temperature. 
Table 4 Temperatures-related life loss per death (95\% eCl) by development level

\begin{tabular}{|c|c|c|c|c|c|c|}
\hline \multirow[t]{2}{*}{ Subgroups } & \multicolumn{2}{|l|}{ Total } & \multicolumn{2}{|l|}{ Cold } & \multicolumn{2}{|l|}{ Heat } \\
\hline & HDRs & LDRs & HDRs & LDRs & HDRs & LDRs \\
\hline Nationwide & $1.32(1.23-1.41)$ & $1.91(1.72-2.10)$ & $1.26(1.17-1.35)$ & $1.62(1.45-1.79)$ & $0.06(0.05-0.08)$ & $0.29(0.18-0.40)$ \\
\hline Northern China & $1.16(0.76-1.54)$ & $2.58(2.03-3.23)$ & $0.64(0.37-0.91)$ & $1.38(1.04-1.72)$ & $0.52(0.22-0.82)$ & $1.38(1.04-1.72)$ \\
\hline Southern China & $1.42(1.29-1.56)$ & $1.93(1.71-2.15)$ & $1.38(1.24-1.51)$ & $1.65(1.45-1.82)$ & $0.04(0.03-0.06)$ & $0.28(0.15-0.41)$ \\
\hline Age 0-64 & $2.03(1.17-2.84)$ & $3.03(2.48-3.58)$ & $1.64(1.15-2.10)$ & $2.40(1.94-2.87)$ & $0.39(-0.32-1.05)$ & $0.63(0.31-0.97)$ \\
\hline Age65+ & $1.26(1.15-1.39)$ & $1.59(1.47-1.71)$ & $1.20(1.09-1.32)$ & $1.41(1.31-1.52)$ & $0.06(0.04-0.09)$ & $0.18(0.1-0.10)$ \\
\hline Males & $1.57(1.33-1.79)$ & $1.89(1.64-2.14)$ & $1.48(1.26-1.69)$ & $1.63(1.48-1.78)$ & $0.09(0.03-0.15)$ & $0.26(0.07-0.46)$ \\
\hline Females & $1.15(1.04-1.27)$ & $1.66(1.42-1.87)$ & $1.08(0.96-1.19)$ & $1.43(1.23-1.61)$ & $0.08(0.06-0.09)$ & $0.22(0.10-0.37)$ \\
\hline Cardiovascular diseases & $1.42(1.21-1.61)$ & $1.90(1.67-2.15)$ & $1.22(1.02-1.40)$ & $1.61(1.50-1.73)$ & $0.20(0.11-0.28)$ & $0.29(0.09-0.50)$ \\
\hline Respiratory diseases & $1.31(1.01-1.62)$ & $1.53(1.11-1.90)$ & $1.11(0.89-1.32)$ & $0.88(0.76-0.99)$ & $0.21(-0.03-0.45)$ & $0.65(0.26-1.01)$ \\
\hline
\end{tabular}

Notes: HDRs High-development regions, LDRs Low-development regions

Cold: temperature below minimum YLLs temperature; Heat: temperature above minimum YLLs temperature.

we found that AF and life loss per death resulting from non-optimal temperature were greater in LDRs than that in HDRs in most subgroups. However, we found the opposite results for patients with RESP disease. This may be owing to AFs determined by both attributable YLL rates and temperature distribution. Compared with HDR, the attributable YLL rates of RESP in LDR are just little higher and were offset by a larger proportion of days around MYT with very low attributed YLL rates in LDRs (Figure S5, see Supplementary material), which might lead to lower attributable YLLs in LDRs for the RESP subgroups compared with HDRs.

We further calculated attributable YLLs and life loss per death for separated temperature components and the results showed that moderate cold was responsible for most attributable YLLs and life loss per death in both LDRs and HDRs. This finding is in line with previous studies based on death counts $[2,6]$. However, most previous research focused on the health impact of extreme temperature and public health policies of adaptive interventions were designed mainly for extreme climate events [34]. In the future, more public health measures should be taken targeting moderate cold to effectively reduce temperature-related mortality burdens.

The present study has several strengths. First, a national multi-location analysis enabled us to synthetically estimate the effect of ambient temperature in various development level regions. Second, we utilized a population adjusted YLL rate to estimate the temperature-YLL associations, which allowed us to directly compare the effects of temperature exposure on YLLs among different regions. Last, we used the high-resolution interpolated temperatures and instead of fixed-site monitor data for temperature exposure of each location, which may reduce exposure measurement error.

Some limitations of our study cannot be ignored. First, it was an ecological study, and hence, some inherent limitations made us unable to take individual exposure

\section{Extreme heat Moderate heat Moderate cold Extreme cold}

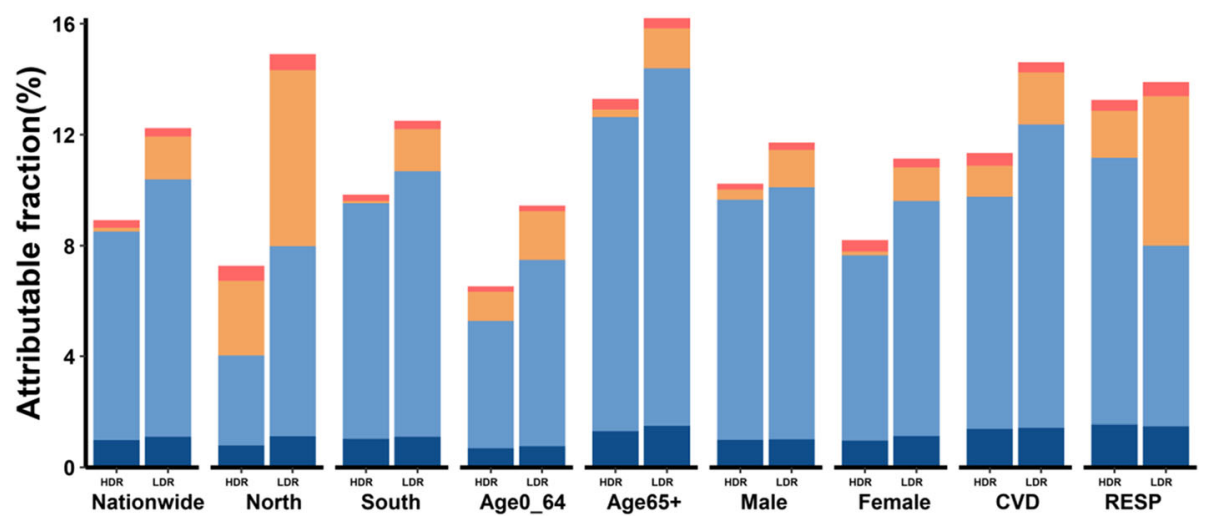

Fig. 4 Attributable fraction of YLLs for separated temperature components. HDR: high-development region; LDR: low-development region; CVD: cardiovascular diseases; RESP: respiratory diseases 
into account. Second, there were not enough study locations in northwest China and southwest China because of the unavailability of mortality data. Third, the study periods in all locations were inconsistent due to the unavailability of death data. However, a study conducted in Shanghai indicated that both heat and cold effects on mortality did not substantially change during 2001-2012 [35].

\section{Conclusion}

This study investigated the associations of temperature and YLL rate in different development regions. Compared with HDRs, for all subpopulations, cold-related YLL rates were higher in LDRs, while YLL rates attributable to heat were similar. Life loss per death attributable to nonoptimal temperatures were more in LDRs than in HDRs, and most of them were from moderate cold. Our findings have important implications for developing targeted adaptive policies to reduce the temperature-related mortality burden in different development regions.

\section{Supplementary information}

Supplementary information accompanies this paper at https://doi.org/10. 1186/s12940-020-00653-3.

Additional file 1. Supplementary Material.

\section{Abbreviations}

AF: Attributable fraction; CDC: Center for Disease Control and Prevention; CVD: Cardiovascular disease; DALY: Disability adjusted life years;

DLNM: Distributed lag non-linear models; DSPs: Disease Surveillance Points System; eCls: Empirical confidence intervals; GDP: Gross domestic product; HDRs: High development regions; LDRs: Low socioeconomic development regions; MYT: Minimum YLL rate temperature; MYP: Minimum YLL rate temperature percentile; RESP: Respiratory disease; RMSE: Root mean squared prediction error; YLL: Years of life lost

\section{Acknowledgements}

We are very thankful to all the study participants.

\section{Authors' contributions}

WM set up the collaborative network, designed the study and revised the manuscript. SC and YX (Yize Xiao) performed the statistical analysis and took the lead in drafting the manuscript and interpreting the results. $M Z, C Z, M Y$, $B H, Y X$ (Yanjun Xu), TL, JH, XX, LL, RH, ZH, JL, DJ, MQ, QZ, WG, PY, YX, JX, WZ, $X \mathrm{~L}, \mathrm{LG}, \mathrm{YZ}$ and $\mathrm{CH}$ collected and cleaned the data, and contributed to interpretation of the results and preparation of the submitted version of the manuscript. The author(s) read and approved the final manuscript.

\section{Funding}

This work was supported by the National Key Research and Development Program of China (2018YFA0606200), Guangzhou Science and Technology Project (201704020194), Natural Science Foundation of Guangdong, China (2019A1515011880), and Guangdong Health Innovation Platform.

\section{Availability of data and materials}

Meteorological data can be accessed from the China Meteorological Data Sharing Service System (http://data.cma.cn/).

The mortality data and $\mathrm{R}$ code of this study are available from the corresponding author (mawj@gdiph.org.cn), upon reasonable request.

\section{Ethics approval and consent to participate}

The study was approved by the Ethics Committee of Guangdong Provincial Center for Disease Control and Prevention (2019025).

\section{Consent for publication}

Not applicable.

\section{Competing interests}

The authors declare no conflict of interest.

\section{Author details}

${ }^{1}$ Guangdong Provincial Institute of Public Health, Guangdong Provincial Center for Disease Control and Prevention, No.160, Qunxian Road, Panyu District, Guangzhou 511430, Guangdong, China. ${ }^{2}$ Yunnan Center for Disease Control and Prevention, Kunming 650022, China. ${ }^{3}$ The National Center for Chronic and Noncommunicable Disease Control and Prevention, Beijing 100050, China. ${ }^{4}$ Department of environment and health, Hunan Provincial Center for Disease Control and Prevention, Changsha 450001, China. ${ }^{5}$ Zhejiang Center for Disease Control and Prevention, Hangzhou 310051, Zhejiang, China. ${ }^{6} \mathrm{Jilin}$ Provincial Center for Disease Control and Prevention, Changchun 130062, China. ${ }^{7}$ Guangdong Provincial Center for Disease Control and Prevention, Guangzhou 511430, China. ${ }^{8}$ School of Public Health, Sun Yat-sen University, Guangzhou 510080, China.

Received: 7 July 2020 Accepted: 8 September 2020

Published online: 15 September 2020

References

1. ICPP. Special Report. 2018. Global warming of $1.5^{\circ} \mathrm{C}$. https://www.ipcc.ch/ sr15/(Accessed 1 July 2019).

2. Gasparrini A, Guo Y, Hashizume M, Lavigne E, Zanobetti A, Schwartz J, Tobias A, Tong S, Rocklov J, Forsberg B, et al. Mortality risk attributable to high and low ambient temperature: a multicountry observational study. Lancet. 2015;386(9991):369-75. https://doi.org/10.1016/s0140-6736(14)621140.

3. Guo Y, Gasparrini A, Armstrong B, Li S, Tawatsupa B, Tobias A, Lavigne E, de Sousa Zanotti Stagliorio Coelho M, Leone M, Pan X, et al. Global variation in the effects of ambient temperature on mortality: a systematic evaluation. Epidemiology. 2014;25(6):781-9. https://doi.org/10.1097/ede. 0000000000000165

4. Kim EJ, Kim H. Effect modification of individual- and regional-scale characteristics on heat wave-related mortality rates between 2009 and 2012 in Seoul, South Korea. Sci Total Environ. 2017;595:141-8. https://doi.org/10. 1016/j.scitotenv.2017.03.248.

5. Ma W, Zeng W, Zhou M, Wang L, Rutherford S, Lin H, Liu T, Zhang Y, Xiao J, Zhang $Y$, et al. The short-term effect of heat waves on mortality and its modifiers in China: an analysis from 66 communities. Environ Int. 2015:75: 103-9. https://doi.org/10.1016/j.envint.2014.11.004.

6. Chen R, Yin P, Wang L, Liu C, Niu Y, Wang W, Jiang Y, Liu Y, Liu J, Qi J, et al. Association between ambient temperature and mortality risk and burden: time series study in 272 main Chinese cities. BMJ. 2018;363:k4306. https:// doi.org/10.1136/bmj.k4306.

7. Steenland K, Armstrong B. An overview of methods for calculating the burden of disease due to specific risk factors. Epidemiology. 2006;17(5):5129. https://doi.org/10.1097/01.ede.0000229155.05644.43.

8. Yang J, Ou CQ, Guo Y, Li L, Guo C, Chen PY, Lin HL, Liu QY. The burden of ambient temperature on years of life lost in Guangzhou, China. Sci Rep. 2015:5:12250. https://doi.org/10.1038/srep12250.

9. Yu W, Vaneckova P, Mengersen K, Pan X, Tong S. Is the association between temperature and mortality modified by age, gender and socio-economic status? Sci Total Environ. 2010;408(17):3513-8. https://doi.org/10.1016/j. scitotenv.2010.04.058.

10. Zhang Y, Xiang Q, Yu Y, Zhan Z, Hu K, Ding Z. Socio-geographic disparity in cardiorespiratory mortality burden attributable to ambient temperature in the United States. Environ Sci Pollut Res Int. 2019;26(1):694-705. https://doi. org/10.1007/s11356-018-3653-z.

11. Chen K, Zhou L, Chen X, Ma Z, Liu Y, Huang L, Bi J, Kinney PL. Urbanization level and vulnerability to heat-related mortality in Jiangsu Province, China. Environ Health Perspect. 2016;124(12):1863-9. https://doi.org/10.1289/ ehp204. 
12. Hu K, Guo Y, Hochrainer-Stigler S, Liu W, See L, Yang X, Zhong J, Fei F, Chen $F$, Zhang $Y$, et al. Evidence for urban-rural disparity in temperature-mortality relationships in Zhejiang Province, China. Environ Health Perspect. 2019; 127(3):37001. https://doi.org/10.1289/ehp3556.

13. Zhang Y, Yu C, Bao J, Li X. Impact of temperature on mortality in Hubei, China: a multi-county time series analysis. Sci Rep. 2017;7:45093. https://doi. org/10.1038/srep45093

14. Hajat S, Kosatky T. Heat-related mortality: a review and exploration of heterogeneity. J Epidemiol Community Health. 2010;64(9):753-60. https:// doi.org/10.1136/jech.2009.087999.

15. Lim YH, Bell ML, Kan H, Honda Y, Guo YL, Kim H. Economic status and temperature-related mortality in Asia. Int J Biometeorol. 2015;59(10):140512. https://doi.org/10.1007/s00484-014-0950-1.

16. Liu S, Wu X, Lopez AD, Wang L, Cai Y, Page A, Yin P, Liu Y, Li Y, Liu J, et al. An integrated national mortality surveillance system for death registration and mortality surveillance, China. Bull World Health Organ. 2016;94(1):46-57. https://doi.org/10.2471/blt.15.153148.

17. Yang G, Hu J, Rao KQ, Ma J, Rao C, Lopez AD. Mortality registration and surveillance in China: history, current situation and challenges. Popul Health Metrics. 2005;3(1):3. https://doi.org/10.1186/1478-7954-3-3.

18. Ma W, Wang L, Lin H, Liu T, Zhang Y, Rutherford S, Luo Y, Zeng W, Zhang Y, Wang $X$, et al. The temperature-mortality relationship in China: an analysis from 66 Chinese communities. Environ Res. 2015;137:72-7. https://doi.org/ 10.1016/j.envres.2014.11.016.

19. Selim SZ, Ismail MA. K-means-type algorithms: a generalized convergence theorem and characterization of local optimality. IEEE T Pattern Ana. 1984; 6(1):81-7. https://doi.org/10.1109/TPAMI.1984.4767478.

20. Charrad M, Ghazzali N, Boiteau V. NbClust: determining the best number of clusters in a data set. 2015. Available from: https://cran.r-project.org/web/ packages/NbClust/indexhtml.

21. Zhang J, Liu X, Tan Z, Chen Q. Mapping of the north-south demarcation zone in China based on GIS. J Lanzhou Univ. 2012;48(03):28-33. https://doi. org/10.13885/j.issn.0455-2059.2012.03.020.

22. Liu T, Chen X, Xu Y, Wu W, Tang W, Chen Z, Ji G, Peng J, Jiang Q, Xiao J, et al. Gut microbiota partially mediates the effects of fine particulate matter on type 2 diabetes: evidence from a population-based epidemiological study. Environ Int. 2019;130:104882. https://doi.org/10.1016/j.envint.2019.05. 076.

23. Liu T, Xiao J, Zeng W, Hu J, Liu X, Dong M, Wang J, Wan D, Ma W. A spatiotemporal land-use-regression model to assess individual level longterm exposure to ambient fine particulate matters. MethodsX. 2019;6:2101. https://doi.org/10.1016/j.mex.2019.09.009.

24. Gasparrini A, Armstrong B, Kenward MG. Distributed lag non-linear models. Stat Med. 2010;29(21):2224-34. https://doi.org/10.1002/sim.3940.

25. Gasparrini A, Leone M. Attributable risk from distributed lag models. BMC Med Res Methodol. 2014;14:55. https://doi.org/10.1002/sim.3940.

26. Majdan M, Plancikova D, Maas A, Polinder S, Feigin V, Theadom A, Rusnak M, Brazinova A, Haagsma J. Years of life lost due to traumatic brain injury in Europe: a cross-sectional analysis of 16 countries. PLoS Med. 2017;14(7): e1002331. https://doi.org/10.1371/journal.pmed.1002331.

27. United Nations. Human Development Index (HDI). 2017. Available from : http://hdr.undp.org/en/content/human-development-index-hdi.

28. Hartigan JA, Wong MA. Algorithm AS 136: a k-means clustering algorithm. J R STAT SOC C-APPL. 1979;28(1):100-8. https://doi.org/10.2307/2346830.

29. Macqueen J. Some methods for classification and analysis of MultiVariate observations. Proc of Fifth Berkeley Symposium on Math Stati and Prob 1965.

30. Teknomo K: K-means clustering tutorial. 2008 http://people.revoledu.com/ kardi/tutorial/kMean/.

31. Huang Z, Lin H, Liu Y, Zhou M, Liu T, Xiao J, Zeng W, Li X, Zhang Y, Ebi KL, et al. Individual-level and community-level effect modifiers of the temperature-mortality relationship in 66 Chinese communities. BMJ Open. 2015;5(9):e009172.

32. Heaviside C, Macintyre H, Vardoulakis S. The urban Heat Island: implications for health in a changing environment. Curr Environ Health Rep. 2017:4(3): 296-305. https://doi.org/10.1136/bmjopen-2015-009172.

33. Hu K, Yang X, Zhong J, Fei F, Qi J. Spatially explicit mapping of heat health risk utilizing environmental and socioeconomic data. Environ Sci Technol. 2017;51(3):1498-507. https://doi.org/10.1021/acs.est.6b04355.

34. Xie H, Yao Z, Zhang Y, Xu Y, Xu X, Liu T, Lin H, Lao X, Rutherford S, Chu C, et al. Short-term effects of the 2008 cold spell on mortality in three subtropical cities in Guangdong Province, China. Environ Health Perspect. 2013;121(2):210-6. https://doi.org/10.1289/ehp.1104541.

35. Yang C, Meng X, Chen R, Cai J, Zhao Z, Wan Y, Kan H. Long-term variations in the association between ambient temperature and daily cardiovascular mortality in Shanghai, China. Sci Total Environ. 2015;538:524-30. https://doi. org/10.1016/j.scitotenv.2015.08.097.

\section{Publisher's Note}

Springer Nature remains neutral with regard to jurisdictional claims in published maps and institutional affiliations.
Ready to submit your research? Choose BMC and benefit from:

- fast, convenient online submission

- thorough peer review by experienced researchers in your field

- rapid publication on acceptance

- support for research data, including large and complex data types

- gold Open Access which fosters wider collaboration and increased citations

- maximum visibility for your research: over $100 \mathrm{M}$ website views per year

At BMC, research is always in progress.

Learn more biomedcentral.com/submissions 